\title{
Waste Plastic, the Challenge Facing Developing Countries-Ban It, Change It, Collect It?
}

\author{
Linda Godfrey ${ }^{1,2}$ \\ 1 CSIR Implementation Unit, P.O. Box 395, Pretoria 0001, South Africa; LGodfrey@csir.co.za; \\ Tel.: +27-12 841-4801 \\ 2 Unit for Environmental Sciences and Management, North-West University, Potchefstroom 2520, South Africa
}

Received: 20 November 2018; Accepted: 14 December 2018; Published: 10 January 2019

check for updates

\begin{abstract}
With changing consumption patterns, growing populations and increased urbanisation, developing countries face significant challenges with regards to waste management. Waste plastic is a particularly problematic one, with single-use plastic leaking into the environment, including the marine environment, at an unprecedented rate. Around the world, countries are taking action to minimise these impacts, including banning single-use plastics; changing petroleum-based plastics to alternative bio-benign products such as paper, glass or biodegradable plastics; and improving waste collection systems to ensure that all waste is appropriately collected and reprocessed or safely disposed. However, these "solutions" are often met with resistance, from business, government or civil society, due to the intended and unintended consequences, leaving many questioning the most appropriate solution to reducing the leakage. This paper argues that there is no one single solution to addressing the leakage of plastic into the environment, but that the solution is likely to be a combination of the three approaches, based on local considerations.
\end{abstract}

Keywords: waste; plastic; marine litter; policy; biodegradable; leakage

\section{Introduction}

Recent publications [1-4] have provided valuable insights into the magnitude and extent of global marine plastics. Jambeck et al.'s "Plastic waste inputs from land into the ocean" [1] identified the top 20 countries ranked by mass of mismanaged plastic waste. Twelve of these countries were classified as low-income or lower-middle income countries, five were in Africa. The leakage of waste plastic into the environment is a significant challenge facing developing countries, aggravated by changing consumption patterns (which includes increased consumption of packaging, in particular plastic) and weak waste collection services $[5,6]$.

Public awareness regarding the leakage of waste plastic into the environment, particularly the marine environment, has increased significantly over recent years. This increased awareness, driven by growing concern for the environmental damage caused by plastics, has resulted in a backlash against single-use plastics, such as plastic carrier shopping bags, and plastics found in the food services industry (e.g., plastic straws, stirrers, cups and lids, cutlery, food containers-items typically used "on-the-go") and in the cosmetics industry (e.g., microbeads and cotton-buds).

According to Ocean Conservancy [7], the top 10 items found in coastal clean-ups in 2017, in order of magnitude, included cigarette butts, food wrappers, plastic beverage bottles, plastic bottle caps, plastic grocery bags, other plastic bags, straws, stirrers, plastic take out/away containers, plastic lids and foam take out/away containers. As noted by Ocean Conservancy [8], "For the first time in over three decades, plastics sweep top ten list of items collected during Ocean Conservancy's International Coastal Clean-Up" in 2017. 
These are the "waste products of a throwaway culture that treats plastic as a disposable material rather than a valuable resource to be harnessed" [9].

\section{Government and Business Response}

The leakage of single-use plastic into the environment, and the resultant pressure from civil society, has resulted in action by both government and business. Government has typically resorted to bans on single-use plastics, or economic instruments such as taxes. Some of the earliest bans from developing countries, typically on plastic carrier bags, include the local "ban on delivery or purchasing of goods and materials in plastic wrappers or plastic bags in the state of Sikkim, India" in 1998 (Asia region); a national ban on "plastic bags $<30 \mu$ and a levy on retailer for thicker ones" in South Africa in 2003 (Africa region); and a local "ban on the use of polyethylene bags in Córdoba, Argentina" in 2009 (Central and South America region) [9].

Recent announcements regarding restrictions at national level on a wider array of single-use plastics, include the proposed directive from the European Union to implement consumption reduction and market reduction measures on food containers, cups for beverages, cotton bud sticks, cutlery, plates, stirrers, straws and sticks for balloons, and to push for a $90 \%$ collection rate of single-use plastic bottles [10]. The UK Government has outlined its intentions to "eliminate all avoidable plastic waste" by 2042 through various voluntary and regulatory interventions, in its recently published " $A$ Green Future: Our 25 Year Plan to Improve the Environment" [11]. Perhaps the most ambitious national plan is that of India, where the prime minister has indicated his intent to eliminate all single-use plastic in the country by 2022 [12]. Bans on single-use plastics at city-level have also been implemented, or currently being planned by, amongst others, Montreal, Mumbai, New Delhi, Seattle and Vancouver.

Business has also taken strides to reduce the negative impacts associated with products at end of life. At the World Economic Forum in Davos in January 2018, eleven global brand owners, retailers and packaging companies committed to making $100 \%$ of their packaging reusable, recyclable or compostable by 2025 or earlier. Companies included Amcor, Ecover, evian, L'Oréal, Mars, M\&S, PepsiCo, The Coca-Cola Company, Unilever, Walmart and Werner \& Mertz, with Nestlé joining the list in April 2018 and Colgate-Palmolive joining in June 2018 [13]. A number of global brand owners were also amongst the 250+ companies that signed the New Plastics Economy Global Commitment, at the Our Ocean Conference in Bali in October 2018. One of the aims of the Global Commitment being to "eliminate the plastic we don't need —-the throwaway straws, cutlery and cups; unnecessary packaging and items that can be replaced with better alternatives" [14].

With a strong drive to \#BeatPlasticPollution, the United Nations Environment Programme [9] has provided guidance on actions that the public, private sector entities and governments can take to minimise the production and use of single-use plastics. These include: (i) waste management system improvements, (ii) promotion of eco-friendly alternatives, (iii) social awareness and public pressure and (iv) voluntary reduction strategies and agreements.

\section{The Way Forward}

As countries respond to the leakage of waste plastic into the environment, particularly our oceans, three high-level, and some might argue, competing, "solutions" are emerging in the global discourse-"ban it", "replace it", "close the tap". In other words, (i) ban single-use plastics, as many countries and cities are doing; (ii) replace petroleum-based single-use plastics with alternative bio-benign materials, such as paper, glass or biodegradable plastics; or (iii) improve waste collection coverage and send all collected waste to appropriate end-of-pipe treatment facilities, whether it be engineered landfills, or recycling or recovery centres, thereby ensuring that plastic has little opportunity to "leak" into the environment.

But is it one approach at the expense of the others? The author would argue that countries, cities, businesses must find their "position" within these three options, depending on what they have control over. 


\subsection{Product Bans}

The response typically adopted by governments, where they are unable to improve waste collection services and where they have little control over the design of products in their market, is simply to ban the product (Figure 1). While this started out with single-use plastic carrier bags, this response is growing in popularity for other single-use plastics, as evidenced by recent policy responses [10-12].

Such reduction measures, while theoretically providing a near immediate solution to the problem, is seen as a threat by business, particularly the local plastic sector (manufacturing and imports), that argues the potential job losses that can be expected as a result, complicating often difficult local economic climates.

If poorly implemented and enforced by government, such bans can have significant unintended consequences (e.g., where banned single-use plastic products are smuggled into the country, used, but end up with no end-of-life solution for safe disposal). Smuggling of plastic bags has been reported in many countries, including, in Africa, Cameroon, Rwanda and Kenya.

However, product bans, particularly of single-use plastic food packaging, must be weighed up against the potential risks to food and water security, an issue particularly relevant in developing countries where safe, potable, municipal water supplies are often lacking.

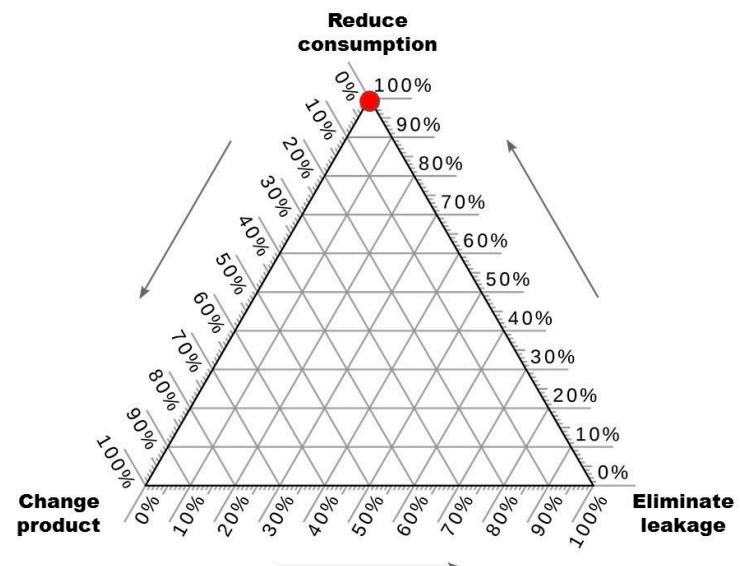

Figure 1. Driving solely a product ban approach.

\subsection{Product Replacement}

The response typically adopted by business (e.g., brand owners and retailers), where they have little control over improving waste collection services, and no appetite for reducing product consumption, is to switch to alternative product designs or materials in an effort to reduce potential reputational damage from their products leaking into the environment (Figure 2).

With limited global success in plastic recycling-only $9 \%$ of all plastic produced has been recycled [15] — product design and material substitution are featuring more and more in businesses' considerations for responsible product management at end-of-life.

Such reduction measures, while theoretically replacing a problematic product with an environmentally benign alternative, are also seen as a threat by business, particularly those that are unwilling or unable to diversify into alternative materials.

However, great care must be taken when implementing such product replacement measures. Examples of switching from plastic carrier bags to biodegradable plastics or to paper bags, has shown that many of these products are not truly biodegradable, or only biodegradable under very specific conditions, often unattainable under normal environmental conditions. Shifts to alternative, bio-benign materials should be informed by a life cycle sustainability assessment, to ensure that net positive environmental, social and economic benefits are achieved. 


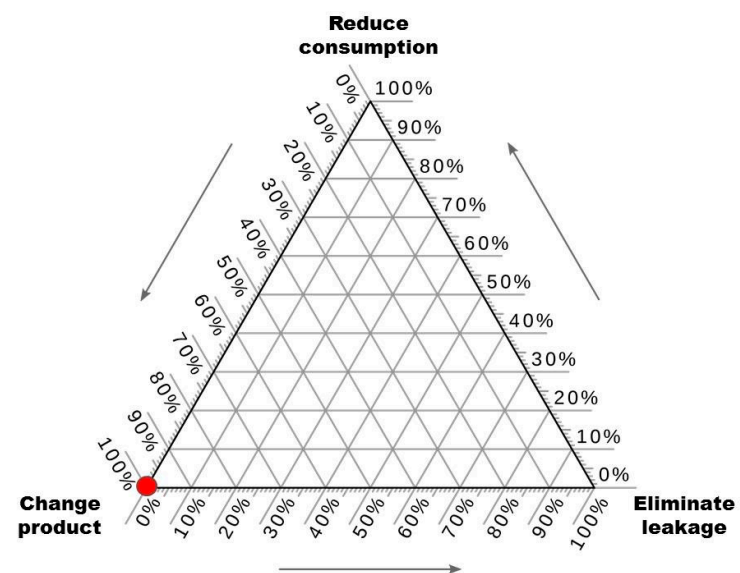

Figure 2. Driving solely a product replacement approach.

\subsection{Improved Waste Collection}

Two billion people are without access to solid waste collection services, with many cities in lowand low-middle income countries having only a 30\%-60\% waste collection coverage [5]. While the Global Waste Management Outlook sets the goal of extending "affordable collection services to all in society, irrespective of income level" [5] (Figure 3), there are many who argue that a $100 \%$ collection rate is unachievable-financially and operationally-due to the governance and capacity constraints facing local municipalities.

Anything less than a $100 \%$ collection coverage means that waste will always "leak", leaving governments with little apparent alternative than to implement product bans, and businesses to explore product replacements.

However, while plastic bans may create a visible difference in plastic litter, it does not solve the environmental problems caused by poor waste management. Without proper collection systems, remaining waste streams, such as other packaging waste (metal, glass, paper), residual waste, household hazardous waste, organic waste or building rubble, still continue to litter the environment. Improving waste collection systems must be a priority in developing countries in order to deal with broader waste management challenges. Improved collection also provides opportunities to grow local reuse, recycling and recovery economies, which are not possible with high levels of uncontrolled dumping. As such, business needs to explore ways of partnering with local municipalities in developing countries, in order to improve waste collection systems, thereby ensuring that their products are collected and responsibly managed at end-of-life.

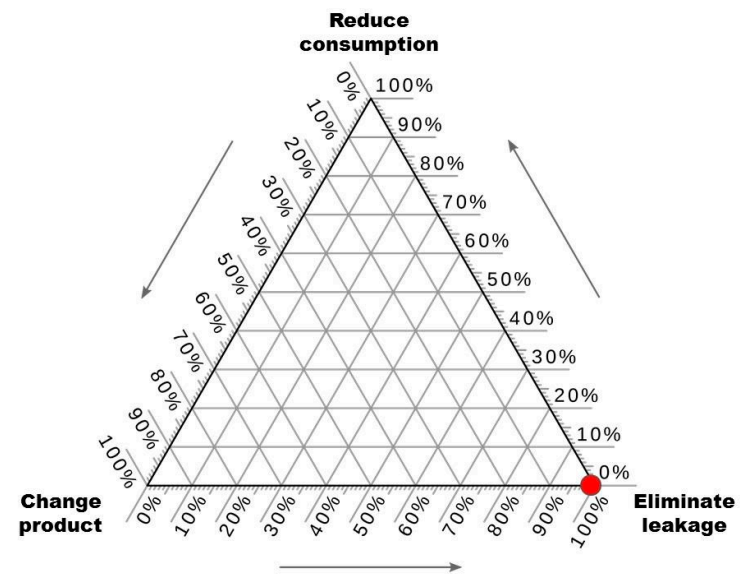

Figure 3. Driving solely a waste collection approach. 


\section{Discussion and Conclusions}

The leakage of plastic into the environment is ultimately an issue of human behaviour. While each of these three "solutions" has an important role to play, we argue that there is no one single solution to addressing the leakage of plastic into the environment, and that the solution is likely to be a combination of all three variables. It is also acknowledged that possible solutions to address the leakage of waste plastic into the environment, and in particular, into the ocean, has been simplified here, and in reality the problem is a much more complex one. However, the intention of the author is to highlight that the solution to waste plastic is not a binary one, but a combination of the three responses, tailored to fit the reality of a city or country depending on what is realistically achievable (Figure 4).
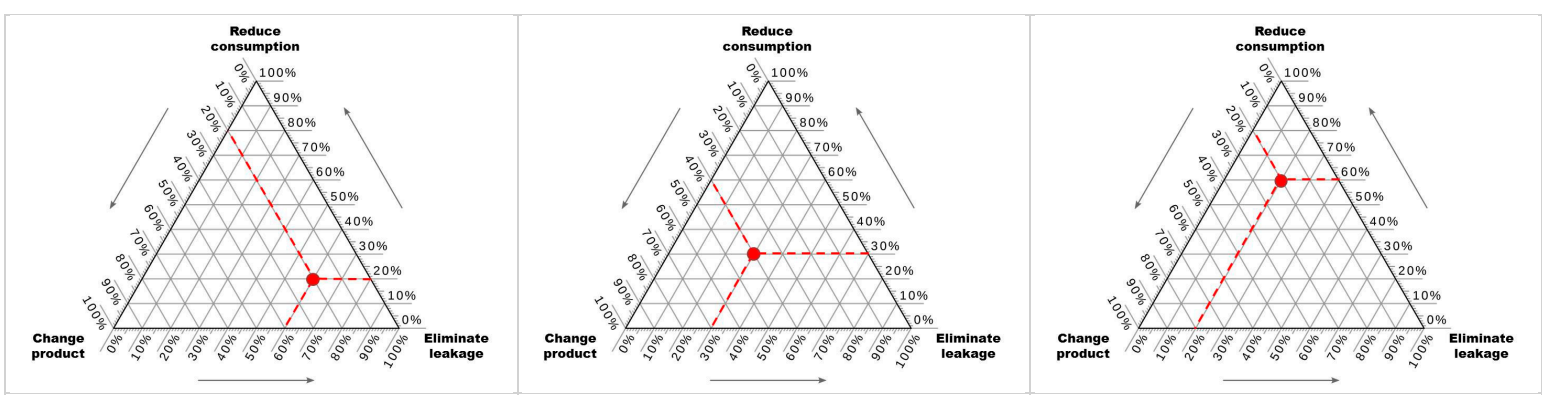

Figure 4. Ternary plot of various localised responses to waste plastic leakage into the environment

For a country like South Africa, where only $61.0 \%$ of households receive a weekly waste collection service [16], the solution is likely to lie in a combination of: (i) improved waste collection; (ii) select product replacement to bio-benign, where it is unlikely to ever be economically viable to recycle certain products at end-of-life; and, if still needed, (iii) regulatory intervention to force the shift.

The question-“Ban it, change it, collect it?" All three of these solutions create opportunities and risks for a country, to differing degrees. Replacement of single-use with multiple-use products (e.g., carrier bags, replacement of petroleum-based single-use plastic with bio-benign alternatives, increased waste collection and recycling), can result in economic (and job) losses in one area, while also creating new opportunities for products and services in another. Which solution will have the greatest impact for a country (i.e., maximum environmental benefit at least "cost" to society)? This decision must be informed by evidence, to ensure that potential unintended consequences are clearly identified and managed.

There is no doubt that the leakage of waste into the environment, and plastic into our oceans, must be stopped. How this is achieved must be determined by each country, based on their set of conditions, in partnership with key stakeholders from business and civil society, and must be appropriate for local conditions.

Author Contributions: The insights provided here are those of the author, L.G.

Funding: This research received no external funding.

Conflicts of Interest: The author declares no conflicts of interest.

\section{References}

1. Jambeck, J.R.; Geyer, R.; Wilcox, C.; Siegler, T.R.; Perryman, M.; Andrady, A.; Narayan, R.; Law, K.L. Plastic waste inputs from land into the ocean. Science 2015, 347, 768-771. [CrossRef] [PubMed]

2. Ocean Conservancy. Stemming the Tide: Land-Based Strategies for a Plastic-Free Ocean. 2015. Available online: https:/ / oceanconservancy.org/wp-content/uploads/2017/04/full-report-stemming-the.pdf (accessed on 14 November 2018).

3. Bergmann, M.; Gutow, L.; Klages, M. Marine Anthropogenic Litter; Springer: Berlin, Germany, 2015; ISBN 978-3-319-16509-7. 
4. Ellen Macarthur Foundation. The New Plastics Economy: Rethinking the Future of Plastics Background to Key Statistics from the Report. February 2016. Available online: https:/ / www.ellenmacarthurfoundation. org/assets/downloads/news/New-Plastics-Economy_Background-to-Key-Statistics_19022016v2.pdf (accessed on 14 November 2018).

5. United Nations Environment Programme (UNEP). Global Waste Management Outlook. 2018. Available online: http:/ / web.unep.org/ourplanet/september-2015/unep-publications/global-waste-managementoutlook (accessed on 15 November 2018).

6. United Nations Environment Programme (UNEP). Africa Waste Management Outlook; United Nations Environment Programme: Nairobi, Kenya, 2018. Available online: https:/ / wedocs.unep.org/bitstream/ handle/20.500.11822/25514/Africa_WMO.pdf?sequence=1\&isAllowed=y (accessed on 27 October 2018).

7. Ocean Conservancy. Building a Clean Swell. International Coastal Cleanup 2018 Report. 2018. Available online: https:/ / oceanconservancy.org/wp-content/uploads/2018/07/Building-A-Clean-Swell.pdf (accessed on 14 November 2018).

8. Ocean Conservancy. Newsroom: Glass Beverage Bottles Edged out as Plastic Production Grows. 2018. Available online: https: / / oceanconservancy.org/news / first-time-three-decades-plastics-sweep-top-tenlist-items-collected-ocean-conservancys-international-coastal-cleanup / (accessed on 11 November 2018).

9. United Nations Environment Programme (UNEP). Banning Single-Use Plastics: Lessons and Experiences from Countries. 2018. Available online: https://wedocs.unep.org/bitstream/handle/20.500.11822/25496/ singleUsePlastic_sustainability.pdf (accessed on 22 October 2018).

10. European Commission. Directive of the European Parliament and of the Council on the Reduction of the Impact of Certain Plastic Products on the Environment, COM (2018) 340 Final. 2018. Available online: http:/ / ec.europa.eu/environment/circular-economy/pdf/single-use_plastics_proposal.pdf (accessed on 15 November 2018).

11. UK Government. A Green Future: Our 25 Year Plan to Improve the Environment. 2018. Available online: https://assets.publishing.service.gov.uk/government/uploads/system/uploads/attachment_data/ file/693158/25-year-environment-plan.pdf (accessed on 15 November 2018).

12. Carrington, D. India will abolish all single-use plastic by 2022, vows Narendra Modi. The Guardian, 5 June 2018. Available online: https://www.theguardian.com/environment/2018/jun/05/india-willabolish-all-single-use-plastic-by-2022-vows-narendra-modi (accessed on 11 November 2018).

13. Ellen MacArthur Foundation. Companies Take Major Step towards a New Plastics Economy. 2018. Available online: https://newplasticseconomy.org/news/11-companies-commit-to-100-reusablerecyclable-or-compostable-packaging-by-2025 (accessed on 14 November 2018).

14. Ellen MacArthur Foundation. The New Plastics Economy Global Commitment. 2018. Available online: https:/ / newplasticseconomy.org/about/open-letter (accessed on 14 November 2018).

15. Geyer, R.; Jambeck, J.R.; Law, K.L. Production, use, and fate of all plastics ever made. Sci. Adv. 2017, 3, 1-5. [CrossRef] [PubMed]

16. Statistics South Africa. The State of Basic Service Delivery in South Africa: In-Depth Analysis of the Community Survey 2016 Data. Report No. 03-01-22-2016. 2017. Available online: http:/ /www.statssa.gov. za/publications/Report\%2003-01-22/Report\%2003-01-222016.pdf (accessed on 11 November 2018).

(C) 2019 by the author. Licensee MDPI, Basel, Switzerland. This article is an open access article distributed under the terms and conditions of the Creative Commons Attribution (CC BY) license (http://creativecommons.org/licenses/by/4.0/). 